\title{
Appendicular Skeleton, Trunk, Skull, and Facial Bones Cancer pT3 TNM Finding v8
}

National Cancer Institute

\section{Source}

National Cancer Institute. Appendicular Skeleton, Trunk, Skull, and Facial Bones Cancer pT3 TNM Finding v8. NCI Thesaurus. Code C136581.

Appendicular skeleton, trunk, skull, and facial bones cancer with discontinuous tumors in the primary bone site. (from AJCC 8th Ed.) 